\title{
TITLE:
}

\section{Targeting TRPs in Neurodegenerative Disorders}

$\operatorname{AUTHOR}(\mathrm{S})$ :

Takada, Yoshinori; Numata, Tomohiro; Mori, Yasuo

\section{CITATION:}

Takada, Yoshinori ...[et al]. Targeting TRPs in Neurodegenerative Disorders. Current Topics in Medicinal Chemistry 2013, 13(3): 322-334

ISSUE DATE:

2013-03-01

URL:

http://hdl.handle.net/2433/189740

\section{RIGHT:}

(c) 2013 Bentham Science Publishers; この論文は出版社版でありません 。引用の際には出版社版をご確認ご利用ください。; This is not the published version. Please cite only the published version. 


\section{Targeting TRPs in neurodegenerative disorders}

Yoshinori Takada ${ }^{1}$, Tomohiro Numata ${ }^{1,2}$, Yasuo Mori ${ }^{1,2}$

${ }^{1}$ Laboratory of Molecular Biology, Department of Synthetic Chemistry and Biological Chemistry, Graduate School of Engineering, and ${ }^{2}$ Laboratory of Environmental Systems Biology, Department of Technology and Ecology, Hall of Global Environmental Studies, Kyoto University, Kyoto 615-8510, Japan.

\section{Author for correspondence:}

Dr Yasuo Mori

Laboratory of Molecular Biology, Department of Synthetic Chemistry and Biological Chemistry, Graduate School of Engineering, Kyoto University, Kyoto 615-8510, Japan.

Tel: +81-75-383-2761

Fax: $+81-75-383-2765$

E-mail: mori@sbchem.kyoto-u.ac.jp

Running title: TRP channels in neurodegenerative disorders 


\section{ABSTRACT}

Neurodegenerative disorders, such as Alzheimer’s disease, Parkinson's disease, Huntington’s disease, and amyotrophic lateral sclerosis present a significant medical challenge in the modern world. Recent evidence indicates that perturbation of neuronal $\mathrm{Ca}^{2+}$ homeostasis is involved in the pathogenesis of these neurodegenerative disorders. Transient receptor potential (TRP) channels are non-selective cation channels that are expressed in various cell types and tissues, and play an important role in regulating $\mathrm{Ca}^{2+}$ signaling in both non-neuronal and neuronal cells. TRP channels are related to the onset or progression of several diseases, and defects in the genes encoding TRP channels (so-called "TRP channelopathies”) underlie certain neurodegenerative disorders due to their abnormal $\mathrm{Ca}^{2+}$ signaling properties. In this article, we review recent findings regarding the relationship between TRPs and neurodegenerative disorders, and discuss the therapeutic potential of targeting TRP channels pharmacologically.

\section{KEYWORDS}

TRP channels, neurodegenerative disorders, oxidative stress, $\mathrm{Ca}^{2+}$ homeostasis, neuronal cell death, Alzheimer's disease, Parkinson's disease, Huntington’s disease, Epilepsy, ataxia, Bipolar disorders, Ischemia, stroke, muscle atrophy, channelopathy

\section{INTRODUCTION}

Many neurodegenerative disorders, including Alzheimer’s disease (AD), Parkinson’s disease (PD), Huntington’s disease (HD) (and related polyglutamine disorders such as spinocerebellar ataxia (SCA)) and amyotrophic lateral sclerosis (ALS), present an enormous medical problem in the modern world because, despite intense investigation of their causes, little progress has been made in developing cures for them. These disorders are distinguished from each other by their clinical symptoms and the specific neuronal sites at which degeneration occurs. AD is characterized by the presence of amyloid plaques and neurofibrillary tangles in the neocortex [1], whereas the anatomical hallmark of PD is the presence of Lewy bodies in the substantia nigra pars compacta [2]. In a mouse model of HD, the translocation of 
truncated huntingtin protein to the nucleus of medium spiny neurons in the striatum is associated with selective degeneration of these cells [3]. ALS is a progressive neurodegenerative disorder involving primarily motor neuronal death in the cerebral cortex, brainstem and spinal cord [4]. However, despite their obvious differences in histological features and disease progression, they share the common feature of progressive neuronal loss, which can be associated with oxidative stress, protein misfolding or aggregation, neuroinflammation, and perturbed neuronal $\mathrm{Ca}^{2+}$ homeostasis [5-7], and might therefore be responsible for the dysfunction or neuronal cell death that is characteristic of these neurodegenerative disorders.

$\mathrm{Ca}^{2+}$ is crucial to neuronal development, signal transduction, and the regulation of a variety of different cellular responses in the nervous system. There is considerable evidence suggesting that disruption of cellular $\mathrm{Ca}^{2+}$ homeostasis plays a critical role in the pathogenesis of neurodegenerative disorders, leading to the breakdown of cellular processes [7]. In fact, chronic exposure to amyloid $\beta$ peptide $(A \beta)$, which is associated with the pathology of $A D$, induces the elevation of intracellular $\mathrm{Ca}^{2+}$ concentration $\left(\left[\mathrm{Ca}^{2+}\right]_{\mathrm{i}}\right)$ and leads to neuronal cell death in cultured hippocampal neurons [8]. Aggregation of $\alpha$-synuclein, which has been implicated in the pathogenesis of PD, induces cell death via disruption of cellular $\mathrm{Ca}^{2+}$ homeostasis [9]. The polyglutamine-expanded huntingtin protein and mutant superoxide dismutase-1, which are involved in the pathogenesis of HD and ALS respectively, also disrupt $\mathrm{Ca}^{2+}$ homeostasis [10, 11]. Therefore, ameliorating the dysfunction of $\mathrm{Ca}^{2+}$ homeostasis may be a viable strategy for ameliorating neurodegenerative disorders.

In many types of cell, $\mathrm{Ca}^{2+}$ influx across the plasma membrane occurs through voltage-dependent, ligand-gated (e.g. nicotinic acetylcholine receptor, $N$-methyl-D-aspartate (NMDA) receptor, etc.), receptor-operated and store-operated $\mathrm{Ca}^{2+}$ channels [12-15]. Several members of the transient receptor potential (TRP) channel family have been implicated in store-operated $\mathrm{Ca}^{2+}$ entry as well as receptor-operated $\mathrm{Ca}^{2+}$ entry, and play an essential role in the regulation of $\left[\mathrm{Ca}^{2+}\right]_{\mathrm{i}}$ [16]. TRPs are non-selective cation channels that are widely expressed in mammalian cells, and are implicated in a variety of cellular functions [17]. In addition, there is growing evidence that TRP channels are related to the onset and progression of an array of disorders, including neurodegeneration [18]. Here, we review the evidence for the involvement of TRP channels in neurodegenerative disorders, and discuss whether TRP channels are putative pharmacological targets for treating these disorders. 


\section{TRP CHANNELS}

The TRP gene was first discovered in Drosophila melanogaster, where trp gene mutants suffer defective photoreception and impaired processing of light-induced signaling in photoreceptor cells [19]. Based on amino acid homology, there are 29 mammalian TRP channels, and this superfamily is divided into six subfamilies: TRPC (canonical), TRPM (melastatin), TRPV (vanilloid), TRPA (ankyrin), TRPP (polycystin) and TRPML (mucolipin) [18]. TRP channels are mostly ubiquitously expressed, and are present in all cellular membranes except for the nuclear envelope and mitochondria. Most TRP channels are localized in the plasma membrane, where they have diverse physiological functions [17, 18, 20]. The TRP channels are proposed to comprise of four subunits, each with six putative transmembrane segments, which assemble as tetramers to form a cation-permeable pore [21, 22]. The intracellular amino (N-) and carboxyl (C-) termini are variable in length and consist of various domains and motifs [17]. The intracellular N-terminal domain of TRPC, TRPV and TRPA contains multiple ankyrin repeats, 33-residue motifs consisting of pairs of antiparallel $\alpha$-helices connected by $\beta$-hairpin motifs. Ankyrin repeat motifs in TRPs seem to be functionally involved in channel tetramerization and interaction with other proteins [23]. The C-terminal domain of the TRPM family also harbors enzymatic motifs, such as the Nudix hydrolase (NudT9-H) domain in TRPM2, which has a low level of ADP-ribose (ADPR) pyrophosphatase activity, despite significant homology with NudT9 ADPR pyrophosphatase [24]. Intracellular ADPR can activate TRPM2 by binding to this C-terminal NudT9-H domain [25, 26]. TRPM6 and TRPM7 contain an atypical serine/threonine protein kinase within the C-terminal domain and this domain bears high similarity to members of the $\alpha$-kinase family. Recently, a functional role of this kinase activity has been demonstrated, with evidence that the kinase domain is cleaved from the ion-conducting pore of TRPM7 by caspase-8 at D1510 in the C-terminus, which appears to disinhibit the TRPM7 channel such that it exhibits substantially higher activity and potentiates Fas receptor signaling [27]. TRPML1 has a serine lipase domain in the intracellular loop between transmembrane domains 1 and 2, a nuclear localization signal and a putative late endosomal-lysosomal targeting signal. TRPML1 also contains a di-leucine motif (L-L-X-X) at the C-terminus, which may target the protein to the lysosome [28]. Nevertheless, despite these divergent features, the TRP channel family shares many common structural features.

Functional characterization of TRPs has revealed that TRP channels are activated by a wide range of stimuli 
including intra- and extracellular messengers, chemical, mechanical, and osmotic stress [17, 18, 29]. For example, many TRP channels are potentiated by phospholipase C (PLC) activation. TRP channels are activated by tyrosine kinase receptors and G-protein-coupled receptors that signal via PLC. Several TRPs are stimulated by changes in redox status, temperature, and $\mathrm{pH}$. This diversity in the activation mechanism of TRPs might underlie the ability of cells to adapt to a multiplicity of environmental changes.

Several channelopathies arising from defective TRP genes have been directly implicated in the pathogenesis of neurodegenerative disorders [30]. Mutations in MCOLN1, which encodes TRPML1, cause mucolipidosis type IV (MLIV), an autosomal-recessive neurodegenerative lysosomal storage disorder [31]. Variants of the TRPM2 and TRPM7 genes have been identified in a subset of Guamanian ALS and Guamanian PD [32, 33]. Recently, mutations in the TRPV4 gene have been shown to cause scapuloperoneal spinal muscular atrophy and Charcot-Marie-Tooth disease type 2C, inherited peripheral neurodegenerative disorders characterized by distal and proximal muscle weakness [34-36]. In addition, $\mathrm{Ca}^{2+}$ signaling via TRPs contributes to the risk of neurodegenerative disorders (as discussed below).

\section{PATHOGENESIS OF NEURODEGENERATIVE DISORDERS}

As mentioned above, neuronal death in neurodegenerative disorders is associated with oxidative stress, neuroinflammation, and excitotoxicity or non-excitotoxicity leading to dysregulation of $\mathrm{Ca}^{2+}$ homeostasis. In this chapter, we explore the involvement of TRP channels in each of these pathogeneses.

\subsection{Oxidative stress}

Under normal conditions, the cellular antioxidant defense systems are sufficient to keep the level of reactive oxygen species (ROS) below a toxic threshold [37]. However, when these defense systems are dysregulated under pathological conditions, oxidative stress occurs due either to an overproduction of ROS or to a failure of the cellular buffering mechanisms [38]. Oxidative stress damages nucleic acids, lipids and proteins, and results in impaired cellular function and the formation of toxic molecules. Oxidative stress also impairs mitochondrial function, which itself generates ROS and further nullifies the antioxidant systems. Excessive generation of ROS leads to the opening of the 
mitochondrial permeability transition pore, release of cytochrome $c$ into the cytoplasm, and induction of an apoptotic cascade [39]. The brain is believed to be vulnerable to oxidative damage because it contains a relatively low level of antioxidants and free-radical-scavenging enzymes [5, 40]. Thus, oxidative stress plays a clear role in neuronal cell death.

ROS are generated by several different pathways, including direct interaction between redox-active metals and oxygen species by reactions such as the Fenton/Haber-Weiss reactions, or by indirect pathways involving the activation of phospholipases, nitric oxide synthase (NOS) and xanthine oxidase [41]. The reduction of molecular oxygen produces superoxide anion radicals $\left(\mathrm{O}_{2}{ }^{-}\right)$, hydrogen peroxide $\left(\mathrm{H}_{2} \mathrm{O}_{2}\right)$, and hydroxyl radicals $\left(\mathrm{OH}^{*}\right)$. $\mathrm{OH}^{\cdot}$ is a highly toxic form that can also be generated from $\mathrm{O}_{2}{ }^{-}-$via Fenton and Haber-Weiss reactions. The pathways for $\mathrm{OH}^{*}$ generation are elevated in the substantia nigra of PD patients [42]. Moreover, $\mathrm{O}_{2}{ }^{--}$reacts with nitric oxide (NO) to produce highly reactive peroxynitrite ( $\left.\mathrm{ONOO}^{-}\right)$, which also regulates excitotoxicity and induces oxidative DNA damage and lipid oxidation [43]. $\mathrm{NO}^{*}$ is a gaseous free radical and an important biological messenger in neurons, and is generated by NOS. NO^ and $\mathrm{ONOO}^{-}$are known as reactive nitrogen species (RNS) and can promote DNA fragmentation by oxidative damage and prevent protein phosphorylation by tyrosine nitration, thereby disturbing signal transduction mediated by tyrosine kinases in $\mathrm{AD}$ [44].

ROS and RNS are normal products of cellular metabolism, but excessive generation leads to dysregulation of intracellular $\mathrm{Ca}^{2+}$ signaling. This dysregulation has been widely observed in neurodegenerative disorders, where aberrant $\mathrm{Ca}^{2+}$ levels stimulate multiple pathways that ultimately induce neuronal cell death [5]. It has been suggested that $\mathrm{Ca}^{2+}$ influx via TRP channels is an important mechanism through which oxidative stress mediates cell death [45]. To date, several TRP channels directly activated by oxidative stress, including TRPC3, TRPC4, TRPC5, TRPM2, TRPM7 and TRPA1 have been identified [45-51].

\subsection{Excitotoxicity and non-excitotoxicity}

Ischemia-induced neuronal hyperexcitation leads to the activation of excitotoxic or non-excitotoxic pathways, which is mediated via ionotropic glutamate receptors or non-glutamate receptors, respectively. Oxidative stress-induced $\mathrm{Ca}^{2+}$ influx can underlie an excitotoxic response, which is originally considered as a pathological situation arising from excessive stimulation of glutamate receptors leading to cell death [52]. The ionotropic family of receptors can be divided 
into pharmacologically distinct subfamilies based on their affinity for NMDA, $\alpha$-amino-3-hydroxy-5-methyl-isoxazole-4-propionate (AMPA) or kainate [53]. NMDA receptors are slow-gating channels that are highly permeable to $\mathrm{Ca}^{2+}$ and $\mathrm{Na}^{+}$, whereas AMPA receptors conduct $\mathrm{K}^{+}$and $\mathrm{Na}^{+}$but are normally impermeable to $\mathrm{Ca}^{2+}$. However, specific neurological insults can drive the formation of $\mathrm{Ca}^{2+}$-permeable AMPA receptors, enhancing the toxicity of endogenous glutamate [54]. When these receptors are excessively stimulated, a huge volume of $\mathrm{Ca}^{2+}$ floods the cytosol through these receptors, exceeding the capacity of the $\mathrm{Ca}^{2+}$-regulatory mechanisms and leading to mitochondrial dysfunction, excessive ROS generation and inappropriate activation of several enzymes (e.g. proteases and endonucleases) that induce apoptotic cascades [55]. Excitotoxicity has been implicated not only in neurological conditions such as stroke, traumatic brain injury and epilepsy, but in neurodegenerative disorders including AD, PD, HD and ALS [52]. Although some glutamate receptor antagonists that control excitotoxic responses have been approved by the US Food and Drug Administration for the treatment of neurodegenerative disorders, their low efficacy, disruption of normal brain function and adverse side effects limit their clinical usefulness.

Accumulated evidence suggests that glutamate receptor-independent non-excitotoxic pathways may exist that also increase cellular $\mathrm{Ca}^{2+}$ levels, one of which is TRP-mediated $\mathrm{Ca}^{2+}$ influx. Thus, agents that modulate TRP channel activity might have potential in treating ischemic brain injuries such as stroke [56, 57].

\subsection{Neuroinflammation}

Neuroinflammatory mechanisms probably contribute to the cascade of events leading to neuronal degeneration. Indeed, prominent activation of inflammatory processes and innate immune responses are observed in the brains of AD patients [58]. Neuroinflammation is mediated by microglial activation, astrogliosis, and lymphocytic infiltration [59]. The involvement of microglia in many acute and chronic neurological diseases has been clearly demonstrated within the last two decades [60]. When neurons in the brain are damaged, microglia are rapidly activated and secrete various inflammatory molecules such as tumor necrosis factor (TNF)- $\alpha$, interleukin (IL)-6, and NO. Activated microglia affect neurons, astrocytes and oligodendrocytes by releasing cytotoxic molecules, including ROS, glutamate, proteases, and neurotoxic cytokines [60]. However, this neuroinflammatory process is implicated not only in the initiation and progression of neuronal degeneration (through the production of deleterious proinflammatory molecules), but also in its 
sequelae. Therefore, there is still intense debate with regard to whether neuroinflammation is a critical causative factor in the pathogenesis of neurodegenerative disorders including AD, PD, and ALS [59, 61, 62].

Some evidence has shown that TRP channels are involved in the neuroinflammatory process. Microglia in brain tissues express TRPV1, a non-selective cation channel. Since TRPV1 activity promotes the generation of ROS by activated microglia, its inhibition would diminish the detrimental effects of microglia in the neurodegenerating brain [63]. Microglia also express TRPV4, activation of which suppresses lipopolysaccharide-induced abnormal activation of microglia [64]. In addition, it has been demonstrated that TRPC3 mediates the astrogliosis induced by brain injury-related factor [65]. However, despite the evidence implicating TRP channels in neuroinflammation, their precise roles and mechanisms in vivo remain unclear.

\section{INVOLVEMENT OF TRPS IN SPECIFIC NEURODEGENERATIVE DISORDERS}

TRP channels have been implicated in the pathophysiology of various neurodegenerative disorders. These disorders, and the channels involved, are summarized in Fig. (1), and discussed in detail in the following sections.

\subsection{Alzheimer's, Parkinson's and Huntington's diseases}

Because of its high metabolic rate and relatively low capacity for cellular regeneration, the brain is believed to be uniquely susceptible to the damaging effects of ROS. Also, the inability of neurons to properly regulate the intracellular $\mathrm{Ca}^{2+}$ concentration $\left(\left[\mathrm{Ca}^{2+}\right]_{\mathrm{i}}\right)$ is linked to the neurodegenerative process [66]. In cases of PD, AD and ALS, various indices of ROS damage have been reported within specific brain regions that undergo selective neurodegeneration [42]. Although variation at the TRPM2 gene has not been conclusively linked with any neurological disease, there is evidence that TRPM2 forms a $\mathrm{Ca}^{2+}$-permeable nonselective cation channel that is present in many neurodegenerative conditions and is activated by ROS. AD is a form of dementia in which patients suffer neurodegeneration and a complete or partial loss of cognitive ability, and can often lead to premature death. In $\mathrm{AD}$, correlations between the pathological hallmarks of $\mathrm{AD}$ (amyloid plaques and neurofibrillary tangles) and perturbed cellular $\mathrm{Ca}^{2+}$ homeostasis have been established in clinical studies of patients, as well as in animal and cell culture models of AD [67]. Specifically, increased levels of A $\beta$ induce 
neurotoxic factors including ROS and cytokines, which impair cellular $\mathrm{Ca}^{2+}$ homeostasis and render neurons vulnerable to apoptosis and excitotoxicity $[68,69]$. The accumulation of $A \beta$ in the striatum is considered to be a key causative factor in $\mathrm{AD}$ [70] because it disrupts cellular $\mathrm{Ca}^{2+}$ homeostasis and induces membrane-associated oxidative stress [71]. Recently, it was reported that TRPM2 is expressed in striatal neurons and is activated by $\mathrm{H}_{2} \mathrm{O}_{2}$ [72-74]. In fact, transfection with a splice variant (TRPM2-S) that acts as a dominant negative inhibitor of TRPM2 function was shown to block both $\mathrm{H}_{2} \mathrm{O}_{2-}$ and $\mathrm{A} \beta$-induced increases in intracellular free- $\mathrm{Ca}^{2+}$ and cell death. Furthermore, TRPM2-specific small interfering RNA reduced TRPM2 mRNA levels and, importantly, limited the toxicity induced by $\mathrm{H}_{2} \mathrm{O}_{2}$ and $\mathrm{A} \beta$ [74]. Interestingly, $\mathrm{A} \beta$ has been suggested to incorporate directly into neuronal membranes where it forms $\mathrm{Ca}^{2+}$-permeable ion channels (amyloid channels) that cause abnormal elevations of intracellular $\mathrm{Ca}^{2+}$ [75]. Since TRPM2 is susceptible to $\mathrm{Ca}^{2+}$-induced activation [76, 77], this supplemental $\mathrm{Ca}^{2+}$ entry would be expected to facilitate further TRPM2 channel activation and cause an exponential elevation of $\left[\mathrm{Ca}^{2+}\right]_{\mathrm{i}}$. Thus, abnormal $\mathrm{Ca}^{2+}$ elevation may be implicated in $\mathrm{A} \beta$-induced neuronal cell death.

Mutations in TRPML1 cause mucolipidosis type IV, another neurodegenerative disease. Recent evidence shows that in many lysosomal storage disorders such as multiple sulfatase deficiency and mucopolysaccharidosis type IIIA, accumulation of undegraded products in lysosomes impairs autophagosome maturation, resulting in accumulation of ubiquitinated protein aggregates and defective mitochondria. These lysosomal storage disorders resemble more common neurodegenerative diseases such as AD, PD and HD [78]. In addition, factors which reduce lysosomal activity (e.g. aging or oxidative stress) could reduce the ability of the autophagy apparatus to eliminate toxic or aggregated proteins, thus exacerbating these age-related neurodegenerative disorders [79].

TRPC channels have been associated with neuronal development, proliferation and differentiation. TRPC channels may also have a role in regulating neurosecretion, long-term potentiation, and synaptic plasticity [80]. Spinocerebellar ataxia type 14 (SCA14) is an autosomal-dominant neurodegenerative disease caused by mutations in protein kinase $\mathrm{C} \gamma(\mathrm{PKC} \gamma)$. These mutations are concentrated in the $\mathrm{C} 1$ domain, which binds diacylglycerol and is necessary for translocation of PKC $\gamma$ and regulation of its kinase activity. The mutants thus fail to phosphorylate TRPC channels, resulting in sustained $\mathrm{Ca}^{2+}$ entry. This altered $\mathrm{Ca}^{2+}$ homeostasis and $\mathrm{Ca}^{2+}$-mediated signaling in Purkinje cells may contribute to the neurodegeneration features characteristic of SCA14. TRPC3 is also involved in the development of 
PD. Parkinsonian movement disorders are often associated with abnormalities in the intensity and pattern of GABA neuron firing in the substantia nigra (SNr); the firing of these neurons is controlled by TRPC3 channels selectively expressed in SNr GABA projection neurons and is crucial to movement control [81]. Although not directly implicated in familial AD, the prospect that TRPC channels could have a role in the onset or progression of AD is intriguing [80]. Collectively, it seems that TRPCs have a 'protean' or bilateral nature that enables them not only to promote neuronal survival, but also to induce neuronal degeneration.

\subsection{Psychiatric and bipolar disorders}

Structural imaging studies have recently demonstrated a putative neuroanatomical basis of bipolar disorder (BD) [82]. Reduction in regional CNS volume and cell numbers (neurons and glia) is observed in many patients [82], and altered intracellular $\mathrm{Ca}^{2+}$ signaling dynamics have been reported [83]. The TRPM2 channel has been implicated in this altered signaling, based on 1) its expression in the striatum (caudate nucleus and putamen); 2) its involvement in processes regulating intracellular $\mathrm{Ca}^{2+}$ homeostasis; 3) its regulation by oxidative stress [84, 85]; and 4) its location on a chromosomal region (21q22.3) known to harbor a BD susceptibility gene(s) [86-88]. Furthermore, its mRNA levels were significantly lower in B lymphoblast cell lines (BLCLs) from BD type I (BD-I) patients with high BLCL basal intracellular $\mathrm{Ca}^{2+}$ concentrations $\left(\left[\mathrm{Ca}^{2+}\right]_{\mathrm{B}}\right)$ compared with those showing normal $\left[\mathrm{Ca}^{2+}\right]_{\mathrm{B}} \cdot\left[\mathrm{Ca}^{2+}\right]_{\mathrm{B}}$ also correlated inversely with TRPM2 mRNA levels in BLCLs from the BD-I group as a whole [89]. Significant association was found between BD-I and a single nucleotide polymorphism (SNP), rs1556314, in exon 11 of the TRPM2 gene in a case-control study [87] and a fine-mapping study [88].

Neuromodulators have functions in a variety of brain diseases. Recent reports have illustrated the important role that neurotrophins play in the regulation of apoptotic neuronal cell death and in the relationship between this machinery and activation of cell survival pathways. BDNF (brain-derived neurotrophic factor) is an important factor in $\mathrm{Ca}^{2+}$-dependent signaling via TRPC3 in hippocampal neurons; the activation of TRPC3 by BDNF affects neurotrophin-initiated dendritic remodeling of pyramidal neurons. siRNA-mediated TRPC3 knockdown and TRPC inhibitors prevented the BDNF-induced increase in spine density and are required for the activation of the sustained membrane depolarization associated with intracellular $\mathrm{Ca}^{2+}$ elevation. Thus, dysfunction of the TRPC3-BDNF signaling 
axis is implicated in mental retardation, in particular Rett Syndrome (RTT), where dendritic spine abnormalities may underlie cognitive impairments [90, 91]. Respiratory irregularities are associated with a deficiency in numerous neuromodulators, such as substance P (SubP). Synaptically-released SubP activates TRPC3/7 to control the regularity of the respiratory rhythm, and dysfunction of the SubP-TRPC3/7 pathway can result in irregular breathing activity [92]. Many of the brain regions associated with RTT are those that exhibit the most dramatic decreases in SubP immunoreactivity, and are mostly involved in the control of the autonomic nervous system, which may explain these irregular breathing activities.

TRPV1 cooperates with the endocannabinoid system and gamma-aminobutyric acid (GABA) and glutamate neurons [93]; cannabinoids may interact with the dopaminergic transmission system in the central nervous system (CNS) and this has an important influence on various dopamine-related neurobiological processes (e.g., control of movement, motivation or reward) and, particularly, on different pathologies affecting these processes, including basal ganglia disorders, schizophrenia and drug addiction. The quest for the discovery of active compounds present in psychoactive plants is driven by the hope of uncovering either novel biochemical pathways in the CNS or molecular leads for drugs to treat mental disorders. Burning Boswellia resin as incense has been part of religious and cultural ceremonies for millennia and is believed to contribute to the spiritual exaltation associated with such events. Incensole acetate (IA), a Boswellia resin constituent, activates TRPV3 and causes anxiolytic- and antidepressant-like behavioral effects with concomitant changes in c-Fos activation in the brain [94]. The standardized extract of the St. John's wort plant (Hypericum perforatum) is commonly used to treat mild-to-moderate depression. Hyperforin, a phloroglucinol derivative of Hypericum perforatum, was identified as an activator of TRPC6 [95] and is known to enhance cognition and facilitate memory. Importantly, it has also been shown to have neuroprotective effects against AD neuropathology, including the ability to disassemble $\mathrm{A} \beta$ aggregates in vitro, decrease astrogliosis and microglial activation, and to improve spatial memory in vivo [96].

\subsection{Western Pacific ALS and muscle atrophy}

Genetic variants of the TRPM2 gene confer a risk of developing Western Pacific amyotrophic lateral sclerosis (ALS) and Parkinsonism-dementia (PD) complex, related neurodegenerative disorders that are found at a relatively high 
incidence on the island of Guam [97]. These foci share a unique mineral environment characterized by the presence of severely low levels of $\mathrm{Ca}^{2+}$ and $\mathrm{Mg}^{2+}$, coupled with high levels of bioavailable transition metals in the soil and drinking water. Epidemiological studies revealed that the presence of heterozygous TRPM2 P1018L also contributes to the etiology of these disorders [33]. Although P1018L forms functional channels that activate in response to ADPR, these channels inactivate quickly and are thus unable to allow sustained ion influx in the presence of physiological concentrations of extracellular $\mathrm{Ca}^{2+}$. This is manifested as an attenuated $\mathrm{Ca}^{2+}$ rise in response to $\mathrm{H}_{2} \mathrm{O}_{2}$. Taking into consideration that intracellular $\mathrm{Ca}^{2+}$ variations affect signaling cascades that control cellular processes including cell death [98-101], decreased TRPM2 activity may dysregulate patterns of $\mathrm{Ca}^{2+}$ signaling to disrupt the coordination of multiple signaling events that maintain cells in homeostasis. This is consistent with the defective $\mathrm{Ca}^{2+}$ handling implicated in many diseases, including neurodegeneration.

Guamanian ALS (ALS-G) and PD (PD-G) are distinct but related neurodegenerative disorders found in high incidence on the Western Pacific Islands of Guam and Rota [97]. Intensive research conducted over many years led to the delineation of a complex interplay between certain environmental and genetic factors [32]. Epidemiological and animal studies have identified two candidate environmental triggers: cycad (traditionally used as a food source in Guam and for medicinal applications in Kii Peninsula and West New Guinea) and its toxin, $\beta$-methylamino-L-alanine (L-BMAA). Cycad was proposed to be involved in the pathogenesis of ALS/PD, and all three high-incidence foci in the Western Pacific (Guam, Kii peninsula, and West New Guinea) were reported to have severely low levels of $\mathrm{Ca}^{2+}$ and $\mathrm{Mg}^{2+}$, coupled with high levels of bioavailable transition metals such as manganese $\left(\mathrm{Mn}^{2+}\right)$, aluminum $\left(\mathrm{Al}^{3+}\right)$, and iron $\left(\mathrm{Fe}^{3+}\right)$ in the soil and drinking water [102]. Epidemiological studies have also implicated genetic factors in the development of ALS/PD because cases cluster in families such that siblings and parents of afflicted patients were found to be at increased risk of developing these diseases. However, segregation studies have yet to yield confirmatory data. The environmental risk factors found in all three hyperendemic Western Pacific foci were used as a screening tool to identify functional candidate susceptibility genes for ALS/PD, i.e. the gene products whose function is most likely to be affected by low $\mathrm{Mg}^{2+}$, low $\mathrm{Ca}^{2+}$ and high transition metal levels [32]. Since most functional candidates were ion channel genes, the study focused mainly on ion channels, primarily those expressed in the CNS and affected by oxidative stress, and found a single candidate gene: TRPM7. TRPM7 resides in chromosome 15q21, within a locus that has been linked to a form of 
autosomal-recessive familial ALS [102]. Indeed, two diseases in humans have been linked to mutations in TRPM7: ALS-G and PD-G. A TRPM7 variant, T1482I, in which the mutated site is located between the channel and the kinase domain, has been found in a subgroup of both ALS-G and PD-G patients but not in matched control subjects [32] Although the T1482I variant has no detectable alteration in $\alpha$-kinase activity, it displays a somewhat higher sensitivity to inhibition by intracellular $\mathrm{Mg}^{2+}$ within the physiologically relevant range. The incidence of both ALS-G and PD-G is increased in environments that are deficient in $\mathrm{Ca}^{2+}$ and $\mathrm{Mg}^{2+}$, such as the west Pacific. Thus increased sensitivity of TRPM7 to inhibition by $\mathrm{Mg}^{2+}$ could aggravate $\mathrm{Mg}^{2+}$ homeostasis in an $\mathrm{Mg}^{2+}$-deficient environment, leading to a reduced intracellular $\mathrm{Mg}^{2+}$ concentration and contributing to the etiology of the neurodegenerative diseases [32].

Mutations in the TRPV4 gene have been linked to three distinct axonal neuropathies. Scapuloperoneal spinal muscle atrophy (SPSMA), congenital distal spinal muscle atrophy (CDSMA), and Charcot-Marie-Tooth disease type 2C (CMT2C, also known as hereditary motor and sensory neuropathy type 2, HMSN IIC) are phenotypically heterogeneous and dominantly-inherited disorders involving topographically distinct muscles and nerves [103]. To date, both gain- and loss-of-function mutants of the TRPV4 $\mathrm{Ca}^{2+}$ channel have been proposed. Spinal muscular atrophies (SMA, also known as hereditary motor neuropathies) and HMSN IIC are clinically and genetically heterogeneous disorders of the peripheral nervous system. Mutations in the TRPV4 gene cause congenital distal SMA, scapuloperoneal SMA, and HMSN IIC. TRPV4 mutations (R269H, R315W and R316C in the N-terminal ankyrin domain) affect channel maturation and lead to reduced surface expression of functional TRPV4 channels [34]. SPSMA and HMSN IIC are phenotypically heterogeneous disorders involving topographically distinct nerves and muscles. Mutations in TRPV4 (R269H and R316C) increase channel activity and alter calcium homeostasis and peripheral neuropathies, implying both a pathogenic mechanism and a putative treatment option for these disorders [35]. HMSN IIC/CMT2C is an autosomal-dominant neuropathy characterized by limb, diaphragm and laryngeal muscle weakness. TRPV4 mutations (R269C and R269H) caused marked cellular toxicity and increased constitutive and activated channel current, which can initiate degeneration of the peripheral nerves. The CMT2C-associated mutations lie in a distinct region of the TRPV4 ankyrin repeats, suggesting that this phenotypic variability may be due to differential effects on regulatory protein-protein interactions [36]. Recently, it was reported that TRPV4 mutants (R269H, R315W and R346C) have a physiological localization and display increased $\mathrm{Ca}^{2+}$ channel activity [103]. Therefore, gain-of-function mutations of TRPV4, which may lead to 
increased intracellular $\mathrm{Ca}^{2+}$ influx, appears to underlie the pathogenesis of TRPV4-linked axonal neuropathies.

\subsection{Ischemia, stroke and traumatic brain injury}

Ischemic or traumatic injury causes a partial disruption of brain integrity or activity [104]. In ischemia or reoxygenation injury and traumatic damage, the brain is susceptible to liberation of catalytic metal ions and their increases in the formation of reactive radicals. Traumatic injury consists of cells dying from necrosis as the primary, irreversible damage associated with the moment of impact. This precipitates a chronic central nervous system inflammation with increased formation of proinflammatory cytokines, enzymes and ROS. ROS are responsible for oxidative stress, which leads to neurodegeneration and linked to programmed cell death [105]. TRPM2 is implicated in inflammatory pathways, specifically as a key participant in monocyte chemokine production induced by $\mathrm{H}_{2} \mathrm{O}_{2}$ [106]. Recently, it was reported that TRPM2 transcript and protein levels were increased in the cerebral cortex and hippocampus of adult male Sprague-Dawley rats following experimental traumatic brain injury, suggesting an involvement of TRPM2 in the sequelae of traumatic brain injuries [107].

TRPC channels form $\mathrm{Ca}^{2+}$ entry pathways, which are essential in maintaining $\mathrm{Ca}^{2+}$ levels in the cytosol, endoplasmic reticulum and mitochondria. Silencing of TRPC1 and TRPC3 inhibits neuronal proliferation, and loss of TRPC1 is implicated in neurodegeneration [108]. Massive neuronal activation by glutamate can result in an excessive rise in cytoplasmic calcium, a process ultimately leading to neuronal death. RNAi mediated knock-down of TRPC1 and application of 2-APB to hippocampal slice cultures both prevented glutamate-induced cell death. Considering that negation of $\mathrm{Ca}^{2+}$ neurotoxicity considerably reduces the neuronal damage stemming from stroke, head trauma and epilepsy, direct and specific inhibition of the TRPC1 channel may be useful in preventing the degeneration of the hippocampal circuitry [109].

TRPM7 is a strong candidate for mediator in anoxic neuronal death and represents an attractive target for neuroprotective treatment of acute CNS injury. There is mounting evidence that TRPM7 channels influence influx of $\mathrm{Ca}^{2+}$ or other cations under excitotoxic conditions. In cultured pyramidal neurons from adult rat hippocampus, the current induced by oxygen/glucose deprivation (OGD), which serves as a model for excitotoxicity, was found to be insensitive to NMDA antagonists [56]. This whole-cell current had the electrophysiological characteristics of TRPM7, and 
siRNA-mediated knockdown of TRPM7 expression reduced ROS production, $\mathrm{Ca}^{2+}$ overload and cell death during OGD [56]. Activation of TRPM7 channels by lowering the extracellular concentration of divalent cations significantly contributes to cell death. These results demonstrate that TRPM7 contributes to the mechanism by which hippocampal neurons detect reductions in extracellular divalent cations, which could explain how TRPM7 induces neuronal death during transient brain ischemia [57]. In addition, activation of TRPM7 by ischemia, OGD, ROS or $\mathrm{H}_{2} \mathrm{O}_{2}$ induces $\mathrm{Ca}^{2+}$ and $\mathrm{Zn}^{2+}$ overload, leading to neuronal dysfunction or death [110-112]. Moreover, excitotoxic conditions may cause upregulation of TRPM7 expression, resulting in a positive feedback loop that has fatal consequences for the cells. Further temporary middle cerebral artery occlusion (MCAO) and OGD causes transient ischemia followed by reperfusion and induces increased expression of TRPM7 in hippocampal neurons [113], which is potentially related to cerebral injury. Interestingly, since NGF suppresses TRPM7 activity [114], intracerebroventricular injection of NGF prior to MCAO prevents the upregulation of TRPM7, implying that reduced levels of TRPM7 levels may be part of the neuroprotective mechanism of NGF [113]. Recently, suppression of TRPM7 channels in vivo was shown to reduce neuronal cell death and preserve function after global cerebral ischemia. In the study, intrahippocampal injections of viral vectors bearing TRPM7-specific short hairpin RNA (shRNA) was used to knock down TRPM7 in hippocampal CA1 pyramidal neurons from adult rat brains. TRPM7 suppression made neurons resistant to ischemic death after brain ischemia following global cerebral ischemia induced by occluding both the common carotid and vertebral arteries and preserved neuronal morphology and function. Also, the shRNA treatment prevented ischemia-induced deficits in LTP and preserved performance in fear-associated and spatial-navigational memory tasks. Thus, regional suppression of TRPM7 is feasible and well-tolerated, and inhibits delayed neuronal death in vivo [115]. Together these results point to a critical, although still poorly understood, role for TRPM7 in the mechanism of neuronal death, which occurs in stroke or brain ischemia and in many neurodegenerative diseases.

Microvascular failure largely underlies the damaging secondary events that accompany traumatic brain injury. Changes in capillary permeability result in the extravasation of extracellular fluid, inflammatory cells, and blood, producing cerebral edema, inflammation, and progressive secondary hemorrhage. The $\mathrm{Ca}^{2+}$-activated TRP channel, TRPM4, is involved in the damaging secondary events that accompany traumatic brain injury [116]. After spinal cord injury, in vivo gene suppression in rats treated with Trpm4 antisense or in $\operatorname{Trpm} 4^{-/-}$mice preserved capillary structural 
integrity, eliminated secondary hemorrhage, yielded a three-to-five-fold reduction in lesion volume and produced a substantial improvement in neurological function [117].

Stroke is one of the leading causes of disability and death. Activation of TRPV3 by incensole acetate (IA) provides a partial protective effect in ischemia. IA acts by inducing ischemic postconditioning, protecting the brain from injury, and is used for treatment and further research of brain injury and neurodegenerative processes [118].

The TRPV4 channel is a $\mathrm{Ca}^{2+}$-permeable cationic channel that is gated by various stimuli such as cell swelling and temperature. After induction of cerebral hypoxia/ischemia by bilateral occlusion of the carotids combined with hypoxic conditions and followed by reperfusion, TRPV4 expression and activity are up-regulated in rat hippocampal astrocytes following ischemia, suggesting that this channel could be involved in $\left[\mathrm{Ca}^{2+}\right]_{i}$ elevation occurring in the astroglial syncytium as a result of an ischemic insult [119].

Thus, TRP channels have significant therapeutic potential as targets for pharmacological therapy of ischemia reperfusion, stroke and traumatic brain injury.

\subsection{Epilepsy and ataxia}

A generalized seizure in the whole animal involves a prolonged depolarization, termed the tonic component of the ictal seizure. The muscarinic-induced long-term depolarization (the plateau potential or tail current) can be a major intrinsic conductance underlying the prolonged depolarization observed during the ictal phase of seizures. It is conceivable that activation of TRPC channels is required for epileptogenesis, for which the trafficking of TRPC channels during activation as a form of desensitization plays a role [120]. The prolonged afterdepolarization following muscarinic stimulation appears to involve increased insertion of TRPC5 channels into the plasma membrane of pyramidal neurons, which play an important role in the generation of prolonged neuronal depolarization and bursting during epileptiform seizure discharges [121]. On the other hand, heteromeric TRPC1/4 channels play a critical role in epileptiform burst firing and seizure-induced neurodegeneration. The large depolarizing plateau potential that underlies the epileptiform burst firing induced by metabotropic glutamate receptor agonists in lateral septal neurons was completely abolished in TRPC1/4 double-knockout mice. These data imply that, TRPC channels could be an unsuspected but critical molecular target for clinical intervention for excitotoxicity [122]. In addition, TRPC3 was identified as a new type of postsynaptic 
cation channel that mediates mGluR-dependent synaptic transmission in cerebellar Purkinje cells and is crucial for motor coordination in TRPC3 knockout mice [123].

TRPCs play a role in hereditary ataxias, a complex group of neurological disorders characterized by the degeneration of the cerebellum and its associated connections. In moonwalker ( $M w k)$ mice, a gain-of-function mutation (T635A) in TRPC3 causes abnormal channel opening, Purkinje cell development and cerebellar ataxia. Growth and differentiation of Purkinje cell dendritic arbors are profoundly impaired in $M w k$ mice. Therefore, TRPC3 is involved in both dendritic development and survival of Purkinje cells mediating cerebellar ataxia [124]. Counter-intuitively, the phenotype of motor coordination defects in TRPC3 knockout mice and moonwalker mice are very similar, despite the nature of the TRPC3 channel activation (loss- vs. gain-of-function) being diametrically opposite [125]. Clearly, additional work is needed to understand the various components of the signaling cascade initiated by TRPC3 in the CNS and the differential connection of this cascade to specific functional outputs in different cell types. Thus, TRPC channels have two distinct functionalities, physiologically regulating neuronal development, but also mediating neuronal degeneration when $\mathrm{Ca}^{2+}$ influx is excessive [108].

TRPV1 seems to be critically involved in the pathogenesis of epilepsy. TRPV1 is now identified as an antiepileptogenic target. Nerve growth factor (NGF) upregulates TRPV1 expression and triggers epileptogenesis. In addition, anandamide (AEA), an endocannabinoid whose levels are increased in epilepsy, activates TRPV1, which can trigger apoptotic neuronal death in chronic epilepsy [126]. In the hippocampus, TRPV1 receptor activation selectively modifies synapses onto interneurons. Therefore, like other forms of hippocampal synaptic plasticity, TRPV1-mediated LTD may have a role in long-term changes in physiological and pathological circuit behavior during learning and epileptic activity [127].

TRPM channels have also been suggested to be responsible for epilepsy. TRPM1 is recognized as a component of the retinal ON bipolar cell transduction channel for congenital stationary night blindness [128]. The microdeletion of TRPM1 in chromosome 15q13.3 causes severe visual impairment demonstrated by optic nerve atrophy, abnormal visual evoked potentials, and an electroretinogram profile consistent with congenital stationary night blindness [129]. Therefore, it could be linked to a complex neurodevelopmental disorder characterized by severe visual impairment as well as hypotonia, profound intellectual disability, and refractory epilepsy. Juvenile myoclonic epilepsy (JME) is the most 
common form of idiopathic generalized epilepsy, accounting for $10-30 \%$ of all epileptics. The gene encoding the EF-hand motif-containing protein, EFHC1, associated with JME interacts with TRPM2, whose activation leads to cell death. In fact, EFHC1 mutation causes JME via mechanisms including neuronal apoptosis [130]. TRPM7 is also involved in the pathogenesis of epilepsy. Lowering extracellular $\mathrm{Ca}^{2+}$ and $\mathrm{Mg}^{2+}$ enhances TRPM7 activity, which can result in the paradoxical $\mathrm{Ca}^{2+}$ influx associated with epilepsy [131].

\subsection{Complications}

Defects in the TRPM6 gene have been associated with the disease the hypomagnesemia with secondary hypocalcemia (HSH) [132, 133], an autosomal recessive disorder that results in electrolyte abnormalities shortly after birth. Affected individuals show severe hypomagnesemia and hypocalcemia, which lead to a multitude of neurological symptoms, including seizures and muscle spasms during infancy, and result in death if untreated. Life-long $\mathrm{Mg}^{2+}$ supplementation is required to overcome the $\mathrm{Mg}^{2+}$ handling defect [132, 133]. Genotype analysis revealed a variety of mutations in the TRPM6 gene in all tested HSH patients [132, 134], including stop, frame-shift, splice-site, and exon deletion mutations [134].

TRPM6 may also contribute to the neurological symptoms of Gitelman syndrome (GS), a condition characterized by deficiencies in the Na-Cl co-transporter (NCC), which is NCC is co-expressed with TRPM6 in the distal tubule of the kidney [135, 136]. Hypomagnesemia develops during chronic hydrochlorothiazide administration and in NCC-knockout mice, accompanied by downregulation of the epithelial $\mathrm{Mg}^{2+}$ channel, TRPM6 [137]. Thus, TRPM6 downregulation may represent a general mechanism involved in the pathogenesis of hypomagnesemia accompanying NCC inhibition or inactivation.

Mutations in the gene MCOLN1 cause mucolipidosis type IV (MLIV, MIM-252650), a recessive, neurodegenerative, lysosomal storage disorder. The disease was classified as a mucolipidosis based on electron microscopy observations that demonstrated the lysosomal storage of laminated, membranous materials (indicating the accumulation of amphiphilic lipids) together with granulated, amorphic vacuoles (indicating water-soluble substances). However, there is considerable variability in the composition of the stored materials between different organs and tissues [138]. MLIV is clinically characterized by severe psychomotor retardation, corneal opacity, retinal degeneration, 
strabismus, agenesis of the corpus callosum, blood iron deficiency, and achlorhydria [138]. Most MLIV patients are first diagnosed at 2-3 years of age and the condition progresses slowly. Despite these early infantile manifestations, most patients thereafter show little or no deterioration clinically for at least the first 2-3 decades of life. Over $80 \%$ of MLIV patients are Ashkenazi Jews; the estimated heterozygote frequency in this population is 1/100 [139]. TRPML1 mutations associated with MLIV have been characterized, and those in the transmembrane regions (the most conserved regions of this family) result in the abolition of mucolipin 1 function. Indeed, all patients possessing these mutations present with a severe clinical phenotype $[138,140]$.

\section{CONCLUDING REMARKS}

The recent evidence regarding the involvement of TRP channels in several diseases has lead to identification of TRP channels as potential drug targets. Capsaicin, a powerful activator of TRPV1, has been approved and used clinically to control abnormal pain in postherpetic neuralgia, diabetic neuropathy and other neuropathic pain conditions. Moreover, TRPV1 and TRPV3 antagonists have advanced to clinical trials [141]. However, in human neurodegenerative disorders, there are currently no drugs that target TRPs. Hyperforin, an activator of TRPC6, has anti-depressant and pro-spatial memory effects in an in vivo model [96], but the translation of these effects to humans has been controversial with clinical trials showing it to have both positive and negative effects [142, 143]. $\mathrm{Ca}^{2+}$ influx via TRPM7 activation is involved in delayed neuronal cell death during transient brain ischemia. Recently, it has been demonstrated that a serine protease inhibitor, nafamostat mesylate, blocks TRPM7 activity in cultured hippocampal neurons [131], suggesting that it may have similar effects to other TRPM7 antagonists such as NDGA, AA861, and MK886, which also have 5-lipoxygenase inhibitory effects and attenuate the cell death associated with TRPM7 activation [144]. Although the efficacy of TRPM7 modulators in vivo has yet to be validated, we are confident that modulators of TRPM7 activity hold great promise as therapeutics for ischemia, stroke and traumatic brain injury. In the future, we believe that many TRP channel agonists and/or antagonists will be developed for the treatment of neurodegenerative disorders. 


\section{REFERENCES}

[1] Glenner, G.G.; Wong, C.W. Alzheimer's disease: initial report of the purification and characterization of a novel cerebrovascular amyloid protein. Biochem. Biophys. Res. Commun., 1984, 120(3), 885-890.

[2] Forno, L.S. Neuropathology of Parkinson's disease. J. Neuropathol. Exp. Neurol., 1996, 55(3), $259-272$.

[3] Hodgson, J.G.; Agopyan, N.; Gutekunst, C.A.; Leavitt, B.R.; LePiane, F.; Singaraja, R.; Smith, D.J.; Bissada, N.; McCutcheon, K.; Nasir, J.; Jamot, L.; Li, X.J.; Stevens, M.E.; Rosemond, E.; Roder, J.C.; Phillips, A.G.; Rubin, E.M.; Hersch, S.M.; Hayden, M.R. A YAC mouse model for Huntington's disease with full-length mutant huntingtin, cytoplasmic toxicity, and selective striatal neurodegeneration. Neuron, 1999, 23(1), 181-192.

[4] Shaw, C.E.; al-Chalabi, A.; Leigh, N. Progress in the pathogenesis of amyotrophic lateral sclerosis. Curr. Neurol. Neurosci. Rep., 2001, 1(1), 69-76.

[5] Barnham, K.J.; Maters, C.L.; Bush, A.I. Neurodegenerative diseases and oxidative stress. Nat. Rev. Drug Discov., 2004, 3(3), 205-214.

[6] Soto, C. Unfolding the role of protein misfolding in neurodegenerative diseases. Nat. Rev. Neurosci., 2003, 4(1), 49-60.

[7] Bezprozvanny, I. Calcium signaling and neurodegenerative diseases. Trends Mol. Med., 2009, 15(3), 89-100.

[8] Mattson, M.P.; Tomaselli, K.J.; Rydel, R.E. Calcium-destabilizing and neurodegenerative effects of aggregated beta-amyloid peptide are attenuated by basic FGF. Brain Res., 1993, 621(1), 35-49.

[9] Danzer, K.M.; Haasen, D.; Karow, A.R.; Moussaud, S.; Habeck, M.; Giese, A.; Kretzschmar, H.; Hengerer, B.; Kostka, M. Different species of alpha-synuclein oligomers induce calcium influx and seeding. J. Neurosci., 2007, 27(34), 9220-9232.

[10] Panov, A.V.; Gutekunst, C.A.; Leavitt, B.R.; Hayden, M.R.; Burke, J.R.; Strittmatter, W.J.; Greenamyre, J.T. Early mitochondrial calcium defects in Huntington's disease are a direct effect of polyglutamines. Nat. Neurosci., 2002, 5(8), 731-736.

[11] Roy, J.; Minotti, S.; Dong, L.; Figlewicz, D.A.; Durham, H.D. Glutamate potentiates the toxicity of mutant $\mathrm{Cu} / \mathrm{Zn}$-superoxide dismutase in motor neurons by postsynaptic calcium-dependent mechanisms. J. Neurosci., 1998, 
18(23), 9673-9684.

[12] Catterall, W.A. Structure and function of neuronal $\mathrm{Ca} 2+$ channels and their role in neurotransmitter release. Cell Calcium, 1998, 24(5-6), 307-323.

[13] Burnashev, N. Calcium permeability of ligand-gated channels. Cell Calcium, 1998, 24(5-6), 325-332.

[14] Barritt, G.J. Receptor-activated Ca2+ inflow in animal cells: a variety of pathways tailored to meet different intracellular Ca2+ signalling requirements. Biochem. J., 1999, 337(Pt 2), 153-169.

[15] Putney, J.W.Jr. Capacitative calcium entry in the nervous system. Cell Calcium, 2003, 34(4-5), 339-344.

[16] Minke, B.; Cook, B. TRP channel proteins and signal transduction. Physiol. Rev., 2002, 82(2), 429-472.

[17] Clapham, D.E. TRP channels as cellular sensors. Nature, 2003, 426(6966), 517-524.

[18] Nilius, B.; Owsianik, G.; Voets, T.; Peters, J.A. Transient receptor potential cation channels in disease. Physiol. Rev., 2007, 87(1), 165-217.

[19] Montell, C.; Rubin, G.M. Molecular characterization of the Drosophila trp locus: a putative integral membrane protein required for phototransduction. Neuron, 1989, 2(4), 1313-1323.

[20] Ramsey, I.S.; Delling, M.; Clapham, D.E. An introduction to TRP channels. Annu. Rev. Physiol., 2006, 68, 619-647.

[21] Goel, M.; Sinkins, W.G.; Schilling, W.P. Selective association of TRPC channel subunits in rat brain synaptosomes. J. Biol. Chem., 2002, 277(50), 48303-48310.

[22] Hofmann, T.; Schaefer, M.; Schultz, G.; Gudermann, T. Subunit composition of mammalian transient receptor potential channels in living cells. Proc. Natl. Acad. Sci. USA, 2002, 99(11), 7461-7466.

[23] Gaudet, R. A primer on ankyrin repeat function in TRP channels and beyond. Mol. BioSyst., 2008, 4(5), 372-379.

[24] Heiner, I.; Eisfeld, J.; Warnstedt, M.; Radukina, N.; Jüngling, E.; Lückhoff, A. Endogenous ADP-ribose enables calcium-regulated cation currents through TRPM2 channels in neutrophil granulocytes. Biochem. J., 2006, 398(2), $225-232$.

[25] Perraud, A.L.; Fleig, A.; Dunn, C.A.; Bagley, L.A.; Launay, P.; Schmitz, C.; Stokes, A.J.; Zhu, Q.; Bessman, M.J.; Penner, R.; Kinet, J.P.; Scharenberg, A.M. ADP-ribose gating of the calcium-permeable LTRPC2 channel revealed by Nudix motif homology. Nature, 2001, 411(6837), 595-599.

[26] Sano, Y.; Inamura, K.; Miyake, A.; Mochizuki, S.; Yokoi, H.; Matsushime, H.; Furuichi, K. Immunocyte Ca2+ 
influx system mediated by LTRPC2. Science, 2001, 293(5533), 1327-1330.

[27] Desai, B.N.; Krapivinsky, G.; Navarro, B.; Krapivinsky, L.; Carter, B.C.; Febvay, S.; Delling, M.; Penumaka, A.; Ramsey, I.S.; Manasian, Y.; Clapham, D.E. Cleavage of TRPM7 releases the kinase domain from the ion channel and regulates its participation in Fas-induced apoptosis. Dev. Cell, 2012, 22(6), 1149-1162.

[28] Sun, M.; Goldin, E.; Stahl, S.; Falardeau, J.L.; Kennedy, J.C.; Acierno, J.S.Jr; Bove, C.; Kaneski, C.R.; Nagle, J.; Bromley, M.C.; Colman, M.; Schiffmann, R.; Slaugenhaupt, S.A. Mucolipidosis type IV is caused by mutations in a gene encoding a novel transient receptor potential channel. Hum. Mol. Genet., 2000, 9(17), 2471-2478.

[29] Numata, T.; Kiyonaka, S.; Kato, K.; Takahashi, N.; Mori, Y. In: Zhu, M. X., editor. TRP Channels. Boca Raton (FL): CRC Press., 2011, Chapter 3.

[30] Nilius, B.; Owsianik, G. Transient receptor potential channelopathies. Pflugers Arch., 2010, 460(2), 437-450.

[31] Raychowdhury, M.K.; González-Perrett, S.; Montalbetti, N.; Timpanaro, G.A.; Chasan, B.; Goldmann, W.H.; Stahl, S.; Cooney, A.; Goldin, E.; Cantiello, H.F. Molecular pathophysiology of mucolipidosis type IV: pH dysregulation of the mucolipin-1 cation channel. Hum. Mol. Genet., 2004, 13(6), 617-627.

[32] Hermosura, M.C.; Nayakanti, H.; Dorovkov, M.V.; Calderon, F.R.; Ryazanov, A.G.; Haymer, D.S.; Garruto, R.M. A TRPM7 variant shows altered sensitivity to magnesium that may contribute to the pathogenesis of two Guamanian neurodegenerative disorders. Proc. Natl. Acad. Sci. USA, 2005, 102(32), 11510-11515.

[33] Hermosura, M.C.; Cui, A.M.; Go, R.C.; Davenport, B.; Shetler, C.M.; Heizer, J.W.; Schmitz, C.; Mocz, G.; Garruto, R.M.; Perraud, A.L. Altered functional properties of a TRPM2 variant in Guamanian ALS and PD. Proc. Natl. Acad. Sci. USA, 2008, 105(46), 18029-18034.

[34] Auer-Grumbach, M.; Olschewski, A.; Papić, L.; Kremer, H.; McEntagart, M.E.; Uhrig, S.; Fischer, C.; Fröhlich, E.; Bálint, Z.; Tang, B.; Strohmaier, H.; Lochmüller, H.; Schlotter-Weigel, B.; Senderek, J.; Krebs, A.; Dick, K.J.; Petty, R.; Longman, C.; Anderson, N.E.; Padberg, G.W.; Schelhaas, H.J.; van Ravenswaaij-Arts, C.M.; Pieber, T.R.; Crosby, A.H.; Guelly, C. Alterations in the ankyrin domain of TRPV4 cause congenital distal SMA, scapuloperoneal SMA and HMSN2C. Nat. Genet., 2010, 42(2), 160-164.

[35] Deng, H.X.; Klein, C.J.; Yan, J.; Shi, Y.; Wu, Y.; Fecto, F.; Yau, H.J.; Yang, Y.; Zhai, H.; Siddique, N.; Hedley-Whyte, E.T.; Delong, R.; Martina, M.; Dyck, P.J.; Siddique, T. Scapuloperoneal spinal muscular atrophy 
and CMT2C are allelic disorders caused by alterations in TRPV4. Nat. Genet., 2010, 42(2), 165-169.

[36] Landouré, G.; Zdebik, A.A.; Martinez, T.L.; Burnett, B.G.; Stanescu, H.C.; Inada, H.; Shi, Y.; Taye, A.A.; Kong, L.; Munns, C.H.; Choo, S.S.; Phelps, C.B.; Paudel, R.; Houlden, H.; Ludlow, C.L.; Caterina, M.J.; Gaudet, R.; Kleta, R.; Fischbeck, K.H.; Sumner, C.J. Mutations in TRPV4 cause Charcot-Marie-Tooth disease type 2C. Nat. Genet., 2010, 42(2), 170-174.

[37] Schulz, J.B.; Lindenau, J.; Seyfried, J.; Dichgans, J. Glutathione, oxidative stress and neurodegeneration. Eur. J. Biochem., 2000, 267(16), 4904-4911.

[38] Yakoubian, T.A.; Standaert, D.G. Targets for neuroprotection in Parkinson's disease. Biochim. Biophys. Acta, 2009, 1792(7), 676-687.

[39] Garrido, C.; Galluzzi, L.; Brunet, M.; Puig, P.E.; Didelot, C.; Kroemer, G. Mechanisms of cytochrome c release from mitochondria. Cell Death Differ., 2006, 13(9), 1423-1433.

[40] Roberts, R.A.; Smith, R.A.; Safe, S.; Szabo, C.; Tjalkens, R.B.; Robertson, F.M. Toxicological and pathophysiological roles of reactive oxygen and nitrogen species. Toxicology, 2010, 276(2), 85-94.

[41] Lewén, A.; Matz, P.; Chan, P.H. Free radical pathways in CNS injury. J. Neurotrauma, 2000, 17(10), 871-890.

[42] Andersen, J.K. Oxidative stress in neurodegeneration: cause or consequence? Nat. Med., 2004, 10 Suppl, S18-25.

[43] Valko, M.; Leibfritz, D.; Moncol, J.; Cronin, M.T.; Mazur, M.; Telser, J. Free radicals and antioxidants in normal physiological functions and human disease. Int. J. Biochem. Cell Biol., 2007, 39(1), 44-84.

[44] Parathath, S.R.; Parathath, S.; Tsirka, S.E. Nitric oxide mediates neurodegeneration and breakdown of the blood-brain barrier in tPA-dependent excitotoxic injury in mice. J. Cell Sci., 2005, 119(Pt 2), 339-349.

[45] Miller, B.A. The role of TRP channels in oxidative stress-induced cell death. J. Membr. Biol., 2006, 209(1), 31-41.

[46] Balzer, M.; Lintschinger, B.; Groschner, K. Evidence for a role of Trp proteins in the oxidative stress-induced membrane conductances of porcine aortic endothelial cells. Cardiovasc. Res., 1999, 42(2), 543-549.

[47] Yoshida, T.; Inoue, R.; Morii, T.; Takahashi, N.; Yamamoto, S.; Hara, Y.; Tominaga, M.; Shimizu, S.; Sato, Y.; Mori, Y. Nitric oxide activates TRP channels by cysteine S-nitrosylation. Nat. Chem. Biol., 2006, 2(11), 596-607.

[48] Sawada, Y.; Hosokawa, H.; Matsumura, K.; Kobayashi, S. Activation of transient receptor potential ankyrin 1 by hydrogen peroxide. Eur. J. Neurosci., 2008, 27(5), 1131-1142. 
[49] Andersson, D.A.; Gentry, C.; Moss, S.; Bevan, S. Transient receptor potential A1 is a sensory receptor for multiple products of oxidative stress. J. Neurosci., 2008, 28(10), 2485-2494.

[50] Bessac, B.F.; Sivula, M.; von Hehn, C.A.; Escalera, J.; Cohn, L.; Jordt, S.E. TRPA1 is a major oxidant sensor in murine airway sensory neurons. J. Clin. Invest., 2008, 118(5), 1899-1910.

[51] Takahashi, N.; Mizuno, Y.; Kozai, D.; Yamamoto, S.; Kiyonaka, S.; Shibata, T.; Uchida, K.; Mori, Y. Molecular characterization of TRPA1 channel activation by cysteine-reactive inflammatory mediators. Channels (Austin), 2008, 2(4), 287-298.

[52] Mattson, M.P. Excitotoxic and excitoprotective mechanisms: abundant targets for the prevention and treatment of neurodegenerative disorders. Neuromolecular Med., 2003, 3(2), 65-94.

[53] Madden, D.R. The structure and function of glutamate receptor ion channels. Nat. Rev. Neurosci., 2002, 3(2), 91-101.

[54] Pellegrini-Giampietro, D.E.; Gorter, J.A.; Bennett, M.V.; Zukin, R.S. The GluR2 (GluR-B) hypothesis: Ca(2+)-permeable AMPA receptors in neurological disorders. Trends Neurosci., 1997, 20(10), 464-470.

[55] Orrenius, S.; Zhivotovsky, B.; Nicotera, P. Regulation of cell death: the calcium-apoptosis link. Nat. Rev. Mol. Cell Biol., 2003, 4(7), 552-565.

[56] Aarts, M.; Iihara, K.; Wei, W.L.; Xiong, Z.G.; Arundine, M.; Cerwinski, W.; MacDonald, J.F.; Tymianski, M. A key role for TRPM7 channels in anoxic neuronal death. Cell, 2003, 115(7), 863-877.

[57] Wei, W.L.; Sun, H.S.; Olah, M.E.; Sun, X.; Czerwinska, E.; Czerwinski, W.; Mori, Y.; Orser, B.A.; Xiong, Z.G.; Jackson, M.F.; Tymianski, M.; MacDonald, J.F. TRPM7 channels in hippocampal neurons detect levels of extracellular divalent cations. Proc. Natl. Acad. Sci. USA, 2007, 104(41), 16323-16328.

[58] Akiyama, H.; Barger, S.; Barnum, S.; Bradt, B.; Bauer, J.; Cole, G.M.; Cooper, N.R.; Eikelenboom, P.; Emmerling, M.; Fiebich, B.L.; Finch, C.E.; Frautschy, S.; Griffin, W.S.; Hampel, H.; Hull, M.; Landreth, G.; Lue, L.; Mrak, R.; Mackenzie, I.R.; McGeer, P.L.; O'Banion, M.K.; Pachter, J.; Pasinetti, G.; Plata-Salaman, C.; Rogers, J.; Rydel, R.; Shen, Y.; Streit, W.; Strohmeyer, R.; Tooyoma, I.; Van Muiswinkel, F.L.; Veerhuis, R.; Walker, D.; Webster, S.; Wegrzyniak, B.; Wenk, G.; Wyss-Coray, T. Inflammation and Alzheimer's disease. Neurobiol. Aging, 2000, 21(3), 383-421. 
[59] Hirsch, E.C.; Hunot, S. Neuroinflammation in Parkinson's disease: a target for neuroprotection? Lancet Neurol., 2009, 8(4), 382-397.

[60] Hanisch, U.K.; Kettenmann, H. Microglia: active sensor and versatile effector cells in the normal and pathologic brain. Nat. Neurosci., 2007, 10(11), 1387-1394.

[61] Streit, W.J. Microglia and neuroprotection: implications for Alzheimer's disease. Brain Res. Rev., 2005, 48(2), 234-239.

[62] Philips, T.; Robberecht, W. Neuroinflammation in amyotrophic lateral sclerosis: role of glial activation in motor neuron disease. Lancet Neurol., 2011, 10(3), 253-263.

[63] Schilling, T.; Eder, C. Importance of the non-selective cation channel TRPV1 for microglial reactive oxygen species generation. J. Neuroimmunol., 2009, 216(1-2), 118-121.

[64] Konno, M.; Shirakawa, H.; Iida, S.; Sakimoto, S.; Matsutani, I.; Miyake, T.; Kageyama, K.; Nakagawa, T.; Shibasaki, K.; Kaneko, S. Stimulation of transient receptor potential vanilloid 4 channel suppresses abnormal activation of microglia induced by lipopolysaccharide. Glia, 2012, 60(5), 761-770.

[65] Shirakawa, H.; Sakimoto, S.; Nakao, K.; Sugishita, A.; Konno, M.; Iida, S.; Kusano, A.; Hashimoto, E.; Nakagawa, T.; Kaneko, S. Transient receptor potential canonical 3 (TRPC3) mediates thrombin-induced astrocyte activation and upregulates its own expression in cortical astrocytes. J. Neurosci., 2010, 30(39), 13116-13129.

[66] Pascale, A.; Etcheberrigaray, R. Calcium alterations in Alzheimer's disease: pathophysiology, models and therapeutic opportunities. Pharmacol. Res., 1999, 39(2), 81-88.

[67] Hölscher, C. Possible causes of Alzheimer's disease: amyloid fragments, free radicals, and calcium homeostasis. Neurobiol. Dis., 1998, 5(3), 129-141.

[68] Varadarajan, S.; Yatin, S.; Aksenova, M.; Butterfield, D.A. Review: Alzheimer's amyloid beta-peptide-associated free radical oxidative stress and neurotoxicity. J. Struct. Biol., 2000, 130(2-3), 184-208.

[69] Eikelenboom, P.; Veerhuis, R.; Scheper, W.; Rozemuller, A.J.; van Gool, W.A.; Hoozemans, J. J. The significance of neuroinflammation in understanding Alzheimer's disease. J. Neural Transm., 2006, 113(11), 1685-1695.

[70] Klunk, W.E.; Engler, H.; Nordberg, A.; Wang, Y.; Blomqvist, G.; Holt, D.P.; Bergström, M.; Savitcheva, I.; Huang, G.; Estrada, S.; Ausén, B.; Debnath, M.L.; Barletta, J.; Price, J.C.; Sandell, J.; Lopresti, B.J.; Wall, A.; Koivisto, P.; 
Antoni, G.; Mathis, C.A.; Långström, B. Imaging brain amyloid in Alzheimer's disease with Pittsburgh Compound-B. Ann. Neurol., 2004, 55(3), 306-319.

[71] Bezprozvanny, I.; Mattson, M. P. Neuronal calcium mishandling and the pathogenesis of Alzheimer's disease. Trends Neurosci., 2008, 31(9), 454-463.

[72] Smith, M.A.; Herson, P.S.; Lee, K.; Pinnock, R.D.; Ashford, M.L. Hydrogen-peroxide-induced toxicity of rat striatal neurones involves activation of a non-selective cation channel. J. Physiol., 2003, 547(Pt 2), 417-425.

[73] Hill, K.; Tigue, N.J.; Kelsell, R.E.; Benham, C.D.; McNulty, S.; Schaefer, M.; Randall, A.D. Characterisation of recombinant rat TRPM2 and a TRPM2-like conductance in cultured rat striatal neurones. Neuropharmacology, 2006, 50(1), 89-97.

[74] Fonfria, E.; Marshall, I.C.; Boyfield, I.; Skaper, S.D.; Hughes, J.P.; Owen, D.E.; Zhang, W.; Miller, B.A.; Benham, C.D.; McNulty, S. Amyloid beta-peptide(1-42) and hydrogen peroxide-induced toxicity are mediated by TRPM2 in rat primary striatal cultures. J. Neurochem., 2005, 95(3), 715-723.

[75] Demuro, A.; Mina, E.; Kayed, R.; Milton, S.C.; Parker, I.; Glabe, C.G. Calcium dysregulation and membrane disruption as a ubiquitous neurotoxic mechanism of soluble amyloid oligomers. J. Biol. Chem., 2005, 280(17), 17294-17300.

[76] Starkus, J.; Beck, A.; Fleig, A.; Penner, R. Regulation of TRPM2 by extra- and intracellular calcium. J. Gen. Physiol., 2007, 130(4), 427-440.

[77] Du, J.; Xie, J.; Yue, L. Intracellular calcium activates TRPM2 and its alternative spliced isoforms. Proc. Natl. Acad. Sci. USA, 2009, 106(17), 7239-7244.

[78] Settembre, C.; Fraldi, A.; Jahreiss, L.; Spampanato, C.; Venturi, C.; Medina, D.; de Pablo, R.; Tacchetti, C.; Rubinsztein, D.C.; Ballabio, A. A block of autophagy in lysosomal storage disorders. Hum. Mol. Genet., 2008, 17(1), 119-129.

[79] Martinez-Vicente, M.; Cuervo, A.M. Autophagy and neurodegeneration: when the cleaning crew goes on strike. Lancet Neurol., 2007, 6(4), 352-361.

[80] Bollimuntha, S.; Selvaraj, S.; Singh, B.B. Emerging roles of canonical TRP channels in neuronal function. Adv. Exp. Med. Biol., 2011, 704, 573-593. 
[81] Zhou, F.W.; Matta, S.G.; Zhou, F.M. Constitutively active TRPC3 channels regulate basal ganglia output neurons. J. Neurosci., 2008, 28(2), 473-482.

[82] Manji, H.K.; Lenox, R.H. The nature of bipolar disorder. J. Clin. Psychiatry, 2000, 61 Supp 13, 42-57.

[83] Wasserman, M.J.; Corson, T.W.; Sibony, D.; Cooke, R.G.; Parikh, S.V.; Pennefather, P.S.; Li, P.P.; Warsh, J.J. Chronic lithium treatment attenuates intracellular calcium mobilization. Neuropsychopharmacology, 2004, 29(4), 759-769.

[84] Uemura, T.; Kudoh, J.; Noda, S.; Kanba, S.; Shimizu, N. Characterization of human and mouse TRPM2 genes: identification of a novel N-terminal truncated protein specifically expressed in human striatum. Biochem. Biophys. Res. Commun., 2005, 328(4), 1232-1243.

[85] Takahashi, N.; Kozai, D.; Kobayashi, R.; Ebert, M.; Mori, Y. Roles of TRPM2 in oxidative stress. Cell Calcium, 2011, 50(3), 279-287.

[86] Nagamine, K.;Kudoh, J.; Minoshima, S.; Kawasaki, K.; Asakawa, S.; Ito, F.; Shimizu, N. Molecular cloning of a novel putative Ca2+ channel protein (TRPC7) highly expressed in brain. Genomics, 1998, 54(1), 124-131.

[87] Xu, C.; Macciardi, F.; Li, P.P.; Yoon, I.S.; Cooke, R.G.; Hughes, B.; Parikh, S.V.; McIntyre, R.S.; Kennedy, J.L.; Warsh, J.J. Association of the putative susceptibility gene, transient receptor potential protein melastatin type 2, with bipolar disorder. Am. J. Med. Genet. B. Neuropsychiatr. Genet., 2006, 141B(1), 36-43.

[88] McQuillin, A.; Bass, N.J.; Kalsi, G.; Lawrence, J.; Puri, V.; Choudhury, K.; Detera-Wadleigh, S.D.; Curtis, D.; Gurling, H.M. Fine mapping of a susceptibility locus for bipolar and genetically related unipolar affective disorders, to a region containing the C21ORF29 and TRPM2 genes on chromosome 21q22.3. Mol. Psychiatry, 2006, 11(2), 134-142.

[89] Yoon, I.S.; Li, P.P.; Siu, K.P.; Kennedy, J.L.; Macciardi, F.; Cooke, R.G.; Parikh, S.V.; Warsh, J.J. Altered TRPC7 gene expression in bipolar-I disorder. Biol. Psychiatry, 2001, 50(8), 620-626.

[90] Amaral, M.D.; Pozzo-Miller, L. TRPC3 channels are necessary for brain-derived neurotrophic factor to activate a nonselective cationic current and to induce dendritic spine formation. J. Neurosci., 2007, 27(19), 5179-5189.

[91] Amaral, M.D.; Chapleau, C.A.; Pozzo-Miller, L. Transient receptor potential channels as novel effectors of brain-derived neurotrophic factor signaling: potential implications for Rett syndrome. Pharmacol. Ther., 2007, 
113(2), 394-409.

[92] Ben-Mabrouk, F.; Tryba, A.K. Substance P modulation of TRPC3/7 channels improves respiratory rhythm regularity and ICAN-dependent pacemaker activity. Eur. J. Neurosci., 2010, 31(7), 1219-1232.

[93] Fernández-Ruiz, J.; Hernández, M.; Ramos, J.A. Cannabinoid-dopamine interaction in the pathophysiology and treatment of CNS disorders. CNS Neurosci. Ther., 2010, 16(3), e72-91.

[94] Moussaieff, A.; Yu, J.; Zhu, H.; Gattoni-Celli, S.; Shohami, E.; Kindy, M.S. Protective effects of incensole acetate on cerebral ischemic injury. Brain Res., 2012, 1443, 89-97.

[95] Leuner, K.; Kazanski, V.; Müller, M.; Essin, K.; Henke, B.; Gollasch, M.; Harteneck, C.; Müller, W.E. Hyperforin--a key constituent of St. John's wort specifically activates TRPC6 channels. FASEB J., 2007, 21(14), 4101-4111.

[96] Griffith, T.N.; Varela-Nallar, L.; Dinamarca, M.C.; Inestrosa, N.C. Neurobiological effects of Hyperforin and its potential in Alzheimer's disease therapy. Curr. Med. Chem., 2010, 17(5), 391-406.

[97] Plato, C.C.; Garruto, R.M.; Galasko, D.; Craig, U.K.; Plato, M.; Gamst, A.; Torres, J.M.; Wiederholt, W. Amyotrophic lateral sclerosis and parkinsonism-dementia complex of Guam: changing incidence rates during the past 60 years. Am. J. Epidemiol., 2003, 157(2), 149-157.

[98] Hara, Y.; Wakamori, M.; Ishii, M.; Maeno, E.; Nishida, M.; Yoshida, T.; Yamada, H.; Shimizu, S.; Mori, E.; Kudoh, J.; Shimizu, N.; Kurose, H.; Okada, Y.; Imoto, K.; Mori, Y. LTRPC2 Ca2+-permeable channel activated by changes in redox status confers susceptibility to cell death. Mol. Cell, 2002, 9(1), 163-173.

[99] Fonfria, E.; Mattei, C.; Hill, K.; Brown, J.T.; Randall, A.; Benham, C.D.; Skaper, S.D.; Campbell, C.A.; Crook, B.; Murdock, P.R.; Wilson, J.M.; Maurio, F.P.; Owen, D.E.; Tilling, P.L.; McNulty, S. TRPM2 is elevated in the tMCAO stroke model, transcriptionally regulated, and functionally expressed in C13 microglia. J. Recept. Signal Transduct. Res., 2006, 26(3), 179-198

[100]Kaneko, S.; Kawakami, S.; Hara, Y.; Wakamori, M.; Itoh, E.; Minami, T.; Takada, Y.; Kume, T.; Katsuki, H.; Mori, Y.; Akaike, A. A critical role of TRPM2 in neuronal cell death by hydrogen peroxide. J. Pharmacol. Sci., 2006, 101(1), 66-76.

[101]Bai, C.X.; Kim, S.; Li, W.P.; Streets, A.J.; Ong, A.C.; Tsiokas, L. Activation of TRPP2 through mDia1-dependent 
voltage gating. EMBO J., 2008, 27(9), 1345-1356.

[102]Hermosura, M.C.; Garruto, R.M. TRPM7 and TRPM2-Candidate susceptibility genes for Western Pacific ALS and PD? Biochim. Biophys. Acta, 2007, 1772(8), 822-835.

[103]Fecto, F.; Shi, Y.; Huda, R.; Martina, M.; Siddique, T.; Deng, H.X. Mutant TRPV4-mediated toxicity is linked to increased constitutive function in axonal neuropathies. J. Biol. Chem., 2011, 286(19), 17281-17291.

[104]Halliwell, B. Reactive oxygen species and the central nervous system. J. Neurochem., 1992, 59(5), $1609-1623$.

[105]Pedersen, S.F.; Owsianik, G.; Nilius, B. TRP channels: an overview. Cell Calcium, 2005, 38(3-4), $233-252$.

[106]Yamamoto, S.; Shimizu, S.; Kiyonaka, S.; Takahashi, N.; Wajima, T.; Hara, Y.; Negoro, T.; Hiroi, T.; Kiuchi, Y.; Okada, T.; Kaneko, S.; Lange, I.; Fleig, A.; Penner, R.; Nishi, M.; Takeshima, H.; Mori, Y. TRPM2-mediated Ca2+influx induces chemokine production in monocytes that aggravates inflammatory neutrophil infiltration. Nat. Med., 2008, 14(7), 738-747.

[107]Cook, N.L.; Vink, R.; Helps, S.C.; Manavis, J.; van den Heuvel, C. Transient receptor potential melastatin 2 expression is increased following experimental traumatic brain injury in rats. J. Mol. Neurosci., 2010, 42(2), 192-199.

[108]Selvaraj, S.; Sun, Y.; Singh, B.B. TRPC channels and their implication in neurological diseases. CNS Neurol. Disord. Drug Targets, 2010, 9(1), 94-104.

[109]Narayanan, K.L.; Irmady, K.; Subramaniam, S.; Unsicker, K.; von Bohlen und Halbach, O. Evidence that TRPC1 is involved in hippocampal glutamate-induced cell death. Neurosci. Lett., 2008, 446(2-3), 117-122.

[110]Inoue, K.; Branigan, D.; Xiong, Z.G. Zinc-induced neurotoxicity mediated by transient receptor potential melastatin 7 channels. J. Biol. Chem., 2010, 285(10), 7430-7439.

[111]Coombes, E.; Jiang, J.; Chu, X.P.; Inoue, K.; Seeds, J.; Branigan, D.; Simon, R.P.; Xiong, Z.G. Pathophysiologically relevant levels of hydrogen peroxide induce glutamate-independent neurodegeneration that involves activation of transient receptor potential melastatin 7 channels. Antioxid. Redox Signal., 2011, 14(10), $1815-1827$.

[112]Nuñez-Villena, F.; Becerra, A.; Echeverría, C.; Briceño, N.; Porras, O.; Armisén, R.; Varela, D.; Montorfano, I.; Sarmiento, D.; Simon, F. Increased expression of the transient receptor potential melastatin 7 channel is critically 
involved in lipopolysaccharide-induced reactive oxygen species-mediated neuronal death. Antioxid. Redox Signal., 2011, 15(9), 2425-2438.

[113]Jiang, H.; Tian, S.L.; Zeng, Y.; Li, L.L.; Shi, J. TrkA pathway(s) is involved in regulation of TRPM7 expression in hippocampal neurons subjected to ischemic-reperfusion and oxygen-glucose deprivation. Brain Res. Bull., 2008, 76(1-2), 124-130.

[114]Tian, S.L.; Jiang, H.; Zeng, Y.; Li, L.L.; Shi, J. NGF-induced reduction of an outward-rectifying TRPM7-like current in rat CA1 hippocampal neurons. Neurosci. Lett., 2007, 419(2), 93-98.

[115]Sun, H.S.; Jackson, M.F.; Martin, L.J.; Jansen, K.; Teves, L.; Cui, H.; Kiyonaka, S.; Mori, Y.; Jones, M.; Forder, J.P.; Golde, T.E.; Orser, B.A.; MacDonald, J.F.; Tymianski, M. Suppression of hippocampal TRPM7 protein prevents delayed neuronal death in brain ischemia. Nat. Neurosci., 2009, 12(10), 1300-1307.

[116]Simard, J.M.; Kahle, K.T.; Gerzanich, V. Molecular mechanisms of microvascular failure in central nervous system injury--synergistic roles of NKCC1 and SUR1/TRPM4. J. Neurosurg., 2010, 113(3), 622-629.

[117]Gerzanich, V.; Woo, S.K.; Vennekens, R.; Tsymbalyuk, O.; Ivanova, S.; Ivanov, A.; Geng, Z.; Chen, Z.; Nilius, B.; Flockerzi, V.; Freichel, M.; Simard, J.M. De novo expression of Trpm4 initiates secondary hemorrhage in spinal cord injury. Nat. Med., 2009, 15(2), 185-191.

[118]Moussaieff, A.; Yu, J.; Zhu, H.; Gattoni-Celli, S.; Shohami, E.; Kindy, M.S. Protective effects of incensole acetate on cerebral ischemic injury. Brain Res., 2012, 1443, 89-97.

[119]Butenko, O.; Dzamba, D.; Benesova, J.; Honsa, P.; Benfenati, V.; Rusnakova, V.; Ferroni, S.; Anderova, M. The increased activity of TRPV4 channel in the astrocytes of the adult rat hippocampus after cerebral hypoxia/ischemia. PLoS One, 2012, 7(6), e39959.

[120]Wang, M.; Bianchi, R.; Chuang, S.C.; Zhao, W.; Wong, R.K. Group I metabotropic glutamate receptor-dependent TRPC channel trafficking in hippocampal neurons. J. Neurochem., 2007, 101(2), 411-421.

[121]Tai, C.; Hines, D.J.; Choi, H.B.; MacVicar, B.A. Plasma membrane insertion of TRPC5 channels contributes to the cholinergic plateau potential in hippocampal CA1 pyramidal neurons. Hippocampus, 2011, 21(9), 958-967.

[122]Phelan, K.D.; Mock, M.M.; Kretz, O.; Shwe, U.T.; Kozhemyakin, M.; Greenfield, L.J.; Dietrich, A.; Birnbaumer, L.; Freichel, M.; Flockerzi, V.; Zheng, F. Heteromeric canonical transient receptor potential 1 and 4 channels play a 
critical role in epileptiform burst firing and seizure-induced neurodegeneration. Mol. Pharmacol., 2012, 81(3), 384-392.

[123]Hartmann, J.; Dragicevic, E.; Adelsberger, H.; Henning, H.A.; Sumser, M.; Abramowitz, J.; Blum, R.; Dietrich, A.; Freichel, M.; Flockerzi, V.; Birnbaumer, L.; Konnerth, A. TRPC3 channels are required for synaptic transmission and motor coordination. Neuron, 2008, 59(3), 392-398.

[124]Becker, E.B.; Oliver, P.L.; Glitsch, M.D.; Banks, G.T.; Achilli, F.; Hardy, A.; Nolan, P.M.; Fisher, E.M.; Davies, K.E. A point mutation in TRPC3 causes abnormal Purkinje cell development and cerebellar ataxia in moonwalker mice. Proc. Natl. Acad. Sci. USA, 2009, 106(16), 6706-6711.

[125]Trebak, M. The puzzling role of TRPC3 channels in motor coordination. Pflugers Arch., 2010, 459(3), 369-375.

[126]Fu, M.; Xie, Z.; Zuo, H. TRPV1: a potential target for antiepileptogenesis. Med. Hypotheses, 2009, 73(1), $100-102$.

[127]Gibson, H.E.; Edwards, J.G.; Page, R.S.; Van Hook, M.J.; Kauer, J.A. TRPV1 channels mediate long-term depression at synapses on hippocampal interneurons. Neuron, 2008, 57(5), 746-759.

[128]Koike, C.; Numata, T.; Ueda, H.; Mori, Y.; Furukawa, T. TRPM1: a vertebrate TRP channel responsible for retinal ON bipolar function. Cell Calcium, 2010, 48(2-3), 95-101.

[129]Lepichon, J.B.; Bittel, D.C.; Graf, W.D.; Yu, S. A 15q13.3 homozygous microdeletion associated with a severe neurodevelopmental disorder suggests putative functions of the TRPM1, CHRNA7, and other homozygously deleted genes. Am. J. Med. Genet. A., 2010, 152A(5), 1300-1304.

[130]Katano, M.; Numata, T.; Aguan, K.; Hara, Y.; Kiyonaka, S.; Yamamoto, S.; Miki, T.; Sawamura, S.; Suzuki, T.; Yamakawa, K.; Mori, Y. The juvenile myoclonic epilepsy-related protein EFHC1 interacts with the redox-sensitive TRPM2 channel linked to cell death. Cell Calcium, 2012, 51(2), 179-185.

[131]Chen, X.; Numata, T.; Li, M.; Mori, Y.; Orser, B.A.; Jackson, M.F.; Xiong, Z.G.; MacDonald, J.F. The modulation of TRPM7 currents by nafamostat mesilate depends directly upon extracellular concentrations of divalent cations. Mol. Brain, 2010, 3, 38.

[132]Walder, R.Y.; Landau, D.; Meyer, P.; Shalev, H.; Tsolia, M.; Borochowitz, Z.; Boettger, M.B.; Beck, G.E.; Englehardt, R.K.; Carmi, R.; Sheffield, V.C. Mutation of TRPM6 causes familial hypomagnesemia with secondary hypocalcemia. Nat. Genet., 2002, 31(2), 171-174. 
[133]Schlingmann, K.P.; Weber, S.; Peters, M.; Niemann Nejsum, L.; Vitzthum, H.; Klingel, K.; Kratz, M.; Haddad, E.; Ristoff, E.; Dinour, D.; Syrrou, M.; Nielsen, S.; Sassen, M.; Waldegger, S.; Seyberth, H.W.; Konrad, M.

Hypomagnesemia with secondary hypocalcemia is caused by mutations in TRPM6, a new member of the TRPM gene family. Nat. Genet., 2002, 31(2), 166-170.

[134]Schlingmann, K.P.; Sassen, M.C.; Weber, S.; Pechmann, U.; Kusch, K.; Pelken, L.; Lotan, D.; Syrrou, M.; Prebble, J.J.; Cole, D.E.; Metzger, D.L.; Rahman, S.; Tajima, T.; Shu, S.G.; Waldegger, S.; Seyberth, H.W.; Konrad, M. Novel TRPM6 mutations in 21 families with primary hypomagnesemia and secondary hypocalcemia. J. Am. Soc. Nephrol., 2005, 16(10), 3061-3069.

[135]Voets, T.; Nilius, B.; Hoefs, S.; van der Kemp, A.W.; Droogmans, G.; Bindels, R.J.; Hoenderop, J.G. TRPM6 forms the Mg2+ influx channel involved in intestinal and renal Mg2+ absorption. J. Biol. Chem., 2004, 279(1), $19-25$.

[136]Cao, G.; Thébault, S.; van der Wijst, J.; van der Kemp, A.; Lasonder, E.; Bindels, R.J.; Hoenderop, J.G. RACK1 inhibits TRPM6 activity via phosphorylation of the fused alpha-kinase domain. Curr. Biol., 2008, 18(3), 168-176.

[137]Nijenhuis, T.; Vallon, V.; van der Kemp, A.W.; Loffing, J.; Hoenderop, J.G.; Bindels, R.J. Enhanced passive Ca2+ reabsorption and reduced Mg2+ channel abundance explains thiazide-induced hypocalciuria and hypomagnesemia. J. Clin. Invest., 2005, 115(6), 1651-1658.

[138]Bach, G. Mucolipin 1: endocytosis and cation channel--a review. Pflugers Arch., 2005, 451(1), 313-317.

[139]Bach, G. Mucolipidosis type IV. Mol. Genet. Metab., 2001, 73(3), 197-203.

[140]Wakabayashi, K.; Gustafson, A.M.; Sidransky, E.; Goldin, E. Mucolipidosis type IV: an update. Mol. Genet. Metab., 2011, 104(3), 206-213.

[141]Moran, M.M.; McAlexander, M.A.; Bíró, T.; Szallasi, A. Transient receptor potential channels as therapeutic targets. Nat. Rev. Drug Discov., 2011, 10(8), 601-620.

[142]Linde, K.; Ramirez, G.; Mulrow, C.D.; Pauls, A.; Weidenhammer, W.; Melchart, D. St John's wort for depression--an overview and meta-analysis of randomised clinical trials. BMJ, 1996, 313(7052), 253-258

[143]Weber, W.; Vander Stoep, A.; McCarty, R.L.; Weiss, N.S.; Biederman, J.; McClellan, J. Hypericum perforatum (St John's wort) for attention-deficit/hyperactivity disorder in children and adolescents: a randomized controlled trial. 
JAMA, 2008, 299(22), 2633-2641

[144]Chen, H.C.; Xie, J.; Zhang, Z.; Su, L.T.; Yue, L.; Runnels, L.W. Blockade of TRPM7 channel activity and cell death by inhibitors of 5-lipoxygenase. PLoS One, 2010, 5(6), e11161 


\section{FIGURE LEGEND}

Involvement of TRPs in specific neurodegenerative disorders, including Alzheimer’s disease (AD), Parkinson's disease (PD), Huntington's disease (HD), mental disorder, bipolar disorder (BD), amyotrophic lateral sclerosis (ALS), muscle atrophy, ischemia, stroke, epilepsy, ataxia, mucolipidosis type IV (MLIV), and hypomagnesemia with secondary hypocalcemia (HSH). 
Fig. (1). (Color)

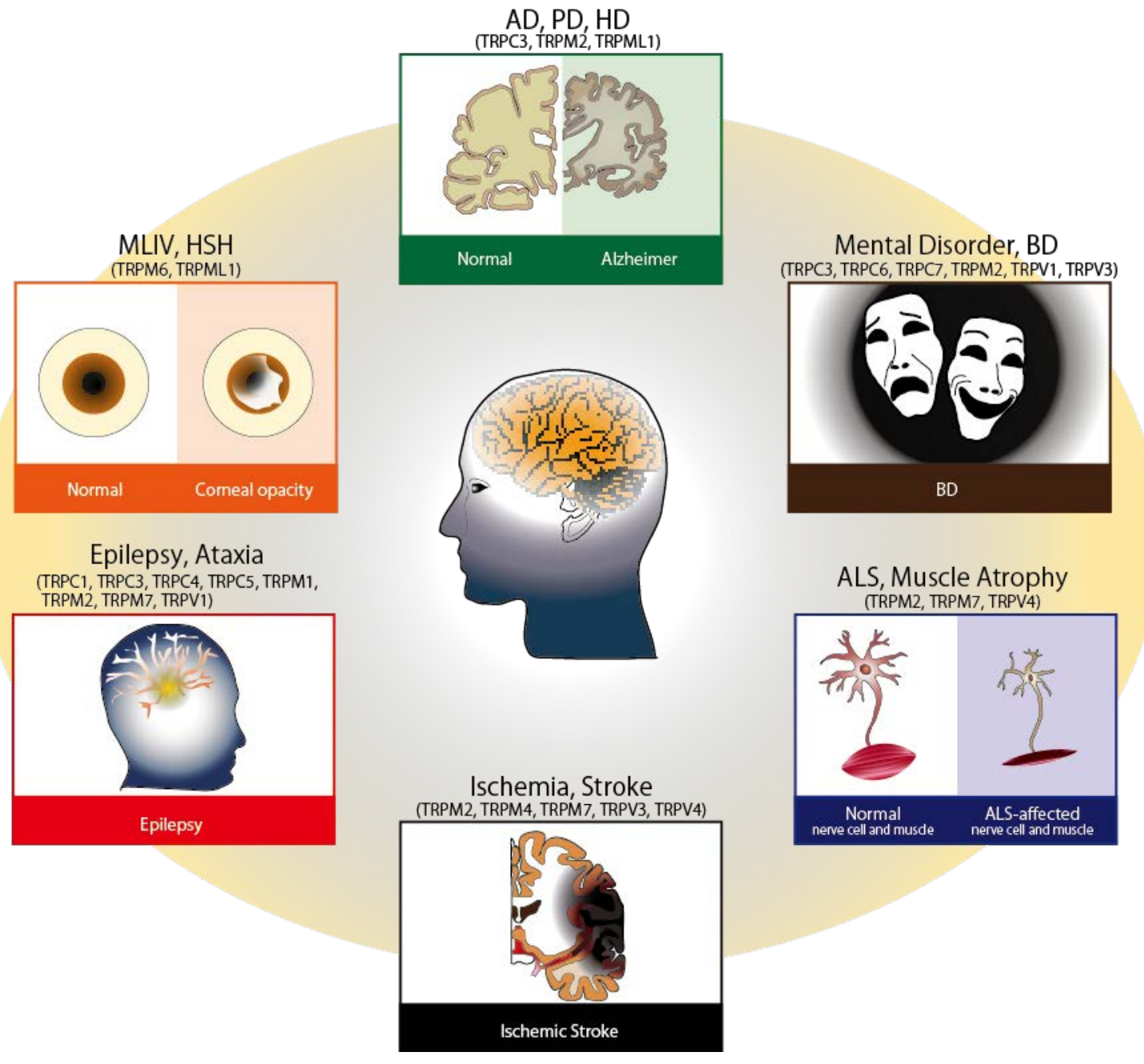


Fig. (1). (B\&W)

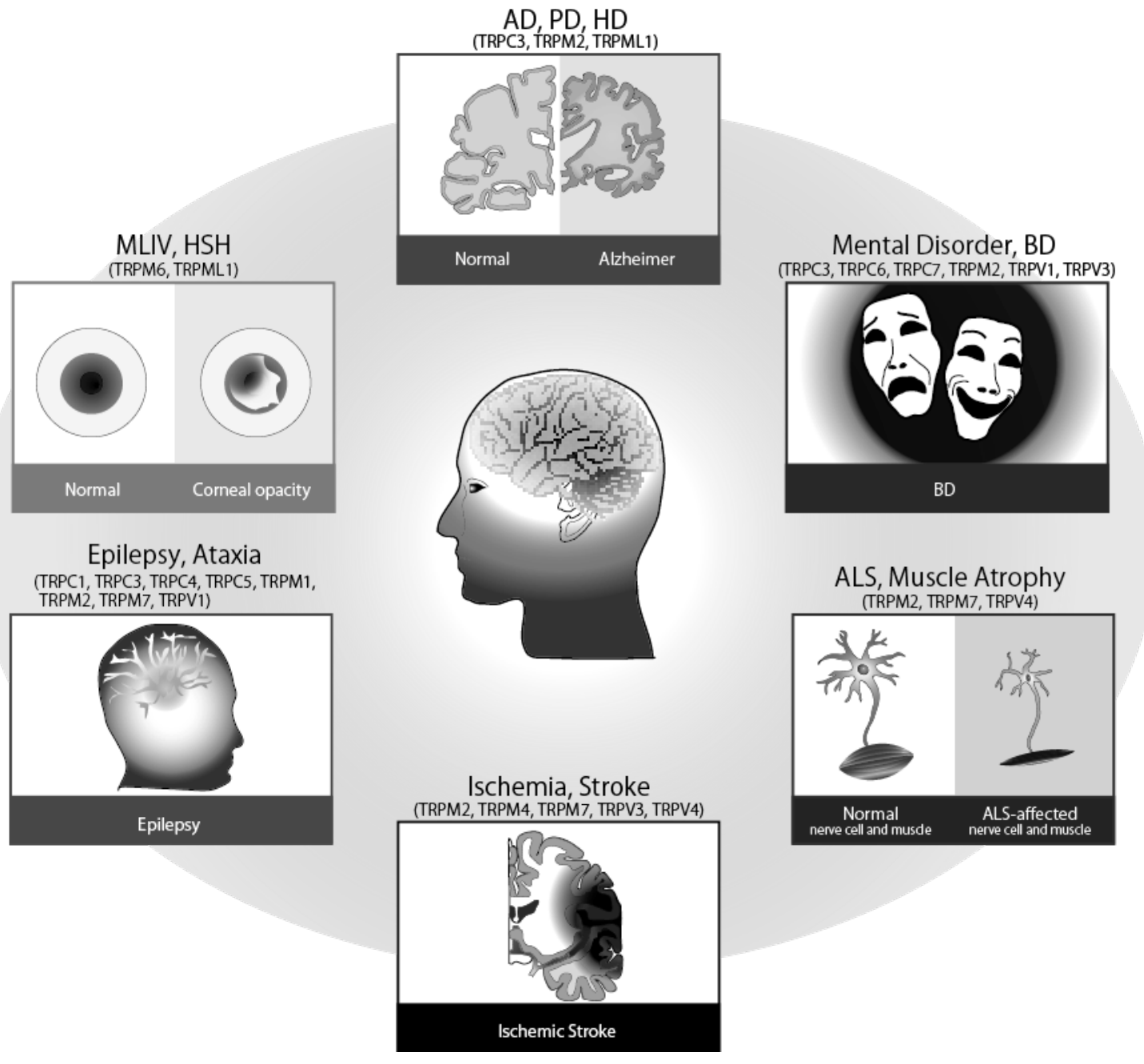

